\title{
Concordance of effects of medical interventions on hospital admission and readmission rates with effects on mortality
}

\author{
Lars G. Hemkens MD MPH, Despina G. Contopoulos-loannidis MD, John P.A. Ioannidis MD DSc
}

\begin{abstract}
Background: Many clinical trials examine a composite outcome of admission to hospital and death, or infer a relationship between hospital admission and survival benefit. This assumes concordance of the outcomes "hospital admission" and "death." However, whether the effects of a treatment on hospital admissions and readmissions correlate to its effect on serious outcomes such as death is unknown. We aimed to assess the correlation and concordance of effects of medical interventions on admission rates and mortality.
\end{abstract}

Methods: We searched the Cochrane Database of Systematic Reviews from its inception to January 2012 (issue 1, 2012) for systematic reviews of treatment comparisons that included meta-analyses for both admission and mortality outcomes. For each meta-analysis, we synthesized treatment effects on admissions and death, from respective randomized trials reporting those outcomes, using random-effects models. We then measured the concordance of directions of effect sizes and the correlation of summary estimates for the 2 outcomes.

Results: We identified 61 meta-analyses including 398 trials reporting mortality and 182 trials reporting admission rates; 125 trials reported both outcomes. In $27.9 \%$ of comparisons, the point estimates of treatment effects for the 2 outcomes were in opposite directions; in $8.2 \%$ of trials, the $95 \%$ confidence intervals did not overlap. We found no significant correlation between effect sizes for admission and death (Pearson $r=0.07, p=$ $0.6)$. Our results were similar when we limited our analysis to trials reporting both outcomes.

Interpretation: In this metaepidemiological study, admission and mortality outcomes did not correlate, and discordances occurred in about one-third of the treatment comparisons included in our analyses. Both outcomes convey useful information and should be reported separately, but extrapolating the benefits of admission to survival is unreliable and should be avoided.
$\mathrm{H}$ ealth care decisions often rely on effects of interventions described using rates of admission or readmission to hospital. ${ }^{1,2}$ These outcomes are typically regarded as indicators of insufficient quality of care and inefficient spending of health care resources, ${ }^{1,2}$ however, whether they can predict other serious clinical outcomes, such as death, is unknown.

Although effects on admission or readmission rates are often analyzed using large sets of routinely collected data, such as from administrative databases and electronic health records, many randomized controlled trials (RCTs) also collect data on admission rates, and some RCTs collect mortality data. Moreover, some trials combine death and admission to hospital as the primary composite outcome ${ }^{3}$ to increase the study's power to detect significant differences and reduce the required study size. ${ }^{4}$ However, the interpretation of such a combination is difficult when the treatment effects on the 2 components are not concordant, ${ }^{5}$ for example, when more patients survive but rates of admission increase. In such cases, composite outcomes may dilute or obscure clinically significant treatment effects on important individual components, ${ }^{4,6}$ and incomplete disclosure of individual effects may mislead the interpretation of the results. ${ }^{4}$

We investigated systematic reviews of treatment comparisons that included meta-analyses of RCTs assessing effects on both rates of admission and mortality. We used the reported trial data to assess whether effects on admission rates were concordant with effects on mortality or whether it was possible to identify interventions and diseases in which these 2 outcomes would provide differing pictures of the merits of the tested interventions.

\section{Methods}

\section{Data identification and eligibility}

We searched the Cochrane Database of Systematic Reviews from its inception to January 2012 (issue 1, 2012) for systematic reviews of treat-
Competing interests: Lars Hemkens received support from The Commonwealth Fund (Harkness Fellowship in Health Care Policy and Practice) for the submitted work. No other competing interests were declared.

This article has been peer reviewed.

Correspondence to:

John P.A. Ioannidis,

jioannid@stanford.edu

CMAJ 2013. DOI:10.1503 /cmaj.130430 
ment comparisons that included meta-analyses of RCTs assessing rates of admission to hospital and meta-analyses of RCTs assessing mortality. We considered any comparison of interventions with drugs, biologics, vaccines or dietary supplements against other interventions, placebo or no treatment. Comparisons of different dosing schemes, routes of administration or timings of application were eligible for inclusion.

We searched the database for the following terms: "hospitalization," "hospital stay," "admission," "readmission" and "mortality." We performed our last search on Jan. 22, 2012 (Appendix 1, available at www.cmaj.ca/lookup/suppl /doi:10.1503/cmaj.130430/-/DC1). Titles and abstracts of retrieved references were screened, and potentially eligible articles were reviewed in full text. We considered Cochrane reviews that included at least 1 meta-analysis on an admission outcome for further analysis. Eligible admission outcomes were stays in hospital for which participants were not admitted at randomization. In patients admitted to hospital, the pertinent outcome was readmission. Length of hospital stay and outcomes indirectly associated with admission, such as retransplantation, were not eligible for inclusion. For topics pertaining to maternal-fetal conditions, we analyzed the outcomes for the mother and fetus separately. For newborns, the pertinent outcome was admission to a neonatal intensive care unit (NICU), because newborns who require hospital care are admitted directly to the NICU. However, for older children and adults, admission specifically to intensive care units was considered beyond the scope of our project and therefore not an eligible outcome.

For each review, all pertinent treatment comparisons reporting an admission outcome were considered separately. For each treatment comparison with an eligible meta-analysis on admission outcomes, we evaluated whether an analysis of mortality was also reported for the same comparison. When both all-cause and cause-specific mortality data were available, we preferred using the former in our analyses.

For both outcomes, we excluded composite outcomes, meta-analyses with fewer than 5 events and analyses without a quantitative data synthesis (when there were 2 or more trials with events). When several subgroup analyses were reported and there was no overall quantitative data synthesis, we selected the subgroup analysis with the most events (or the most trials when this information was missing).

Finally, we excluded comparisons where the experimental intervention could not be clearly defined (based on the approval dates of the interventions [we defined older treatments as controls]).

\section{Data extraction}

Screening and data extraction were performed independently by 2 investigators, and discrepancies were solved by a third.

We extracted the following data for each eligible comparison from the Cochrane review: condition or disease category; interventions compared; category of admission outcome (admission, readmission); type of admission outcome (all cause, cause specific); mortality outcome (all cause, cause specific); comparator (active treatment v. placebo or no treatment); and population (adults v. children). From the individual RCTs included in the meta-analyses, we extracted the numbers of events and the numbers of patients in the intervention and control groups $(2 \times 2$ table). Finally, we captured whether trials reporting on admission rates were double-blind, because the decision to admit to hospital may be subjective and might therefore be biased in unmasked trials. All of the data used for our analyses were included in the Cochrane reviews; we did not use publications of primary studies.

\section{Statistical analysis}

For each included treatment comparison, we used the reported RCT data (i.e., $2 \times 2$ tables) to calculate the summary treatment effect estimate (odds ratios [ORs]) on admission rates and mortality with a random-effects model. ${ }^{7}$ If there were no events in 1 or more study arms, we added 0.5 to all cells of the $2 \times 2$ table to allow for a meaningful calculation of the OR. We omitted comparisons for which only a single trial was available and for which all participants in both groups were admitted to hospital. In cases in which the reported trial-level data did not allow us to calculate the $\mathrm{OR}$, we used the relative risks reported by the review authors with the assumption that they were approximations of the OR. We inverted our results so that an OR of less than 1 corresponded to a decreased risk with the experimental intervention compared with the control.

We examined whether the distribution of estimates differed for the 2 outcomes. We estimated the average intervention effect for an admission outcome and for a mortality outcome across all eligible comparisons using random-effects models. We described the between-comparison heterogeneity using the $I^{2}$ metric and the betweencomparison variance using $\tau^{2}$ and their respective 95\% confidence intervals (CIs). These calculations combine the summary effects of comparison-specific meta-analyses on the same type of outcome into over-arching meta-analyses and provide an estimate of the average and spread of effect sizes typically seen for this outcome across diverse comparisons. 
We recorded the frequency with which we saw the following: the point estimates of the admission and mortality outcomes were concordant or discordant; the effects for each outcome were nominally significant; an intervention significantly decreased the risk of admission while increasing the risk of death (and vice versa); and 95\% CIs of effects did not overlap.

We calculated the correlation between the ORs of effects on rates of admission and mortality using Pearson's correlation coefficient $(r)$. In addition, we considered the uncertainty of the effect estimates by weighting using the inverse of the sum of variances of the effect estimates.

Our sensitivity and subgroup analyses included an analysis with only the results of trials in which rates of admission and mortality were both reported, a comparison of effects for different conditions or diseases, an analysis to investigate all-cause or cause-specific admission and death, an analysis of hospital admissions or readmissions, an analysis to compare effects for different study populations (e.g., adults, children, pregnant women and newborns), an analysis to investigate the use of active comparators, an analysis of admissions from double-blind trials only and an analysis using fixed-effect models. ${ }^{7}$

We performed all analyses using Stata 12.1. We report 2-tailed $p$ values and 95\% CIs.

\section{Results}

We identified 909 potentially eligible reviews (Figure 1), 55 of which met our inclusion criteria (Table 1). These reviews involved 61 treatment comparisons from 398 trials with mortality data and 182 trials with admissions data; 125 RCTs reported both outcomes. Of the 182 trials with admissions data, 115 were double-blind.

Across the comparisons with complete trial data for both outcomes (50/61 comparisons), meta-analyses included a median of 1651 patients (interquartile range [IQR] 764-5114) for mortality outcomes and a median of 971 patients (IQR 379-4387) for admission outcomes (Mann-Whitney $U$ test $p=0.2$ ). More single studies (median 4, IQR 3-9) and a lower median number of events (53, IQR 11-182) were included per meta-analysis on mortality compared with meta-analyses on admission, which included a median of 3 studies (IQR $1-4 ; p<0.01$ ) and 150 events (IQR 63-333; $p<0.01$ ). The event rate was 6-fold higher for admission (median 17.62 per 100 patients, IQR 7.38-37.64) than for death (2.94, IQR 1.08-11.67) $(p<0.01)$. The median year of publication of the trials was 1999 (IQR 1992-2005).

\section{Effect sizes for admissions and death}

In the 61 comparisons, most of the mortality point estimates were between 0.4 and 2.5 (Figure 2); even for the 5 outliers, the $95 \%$ CIs reached well into this region. ${ }^{16,37-39,44}$ There was a somewhat wider spread in the point estimates for admission, with 8 comparisons (from 7 reviews) lying outside the 0.4 to 2.5 range, ${ }^{20,22,26,32,33,34,37}$ for 3 comparisons (from 2 reviews), the $95 \%$ CIs did not reach into this region. ${ }^{32,34}$ Overall, nominally significant effects were seen in 20 of 61 comparisons for admission and 12 of 61 comparisons for death (McNemar test $p=0.1)$. The average OR for admission was 0.82 (95\% CI 0.74-0.91),

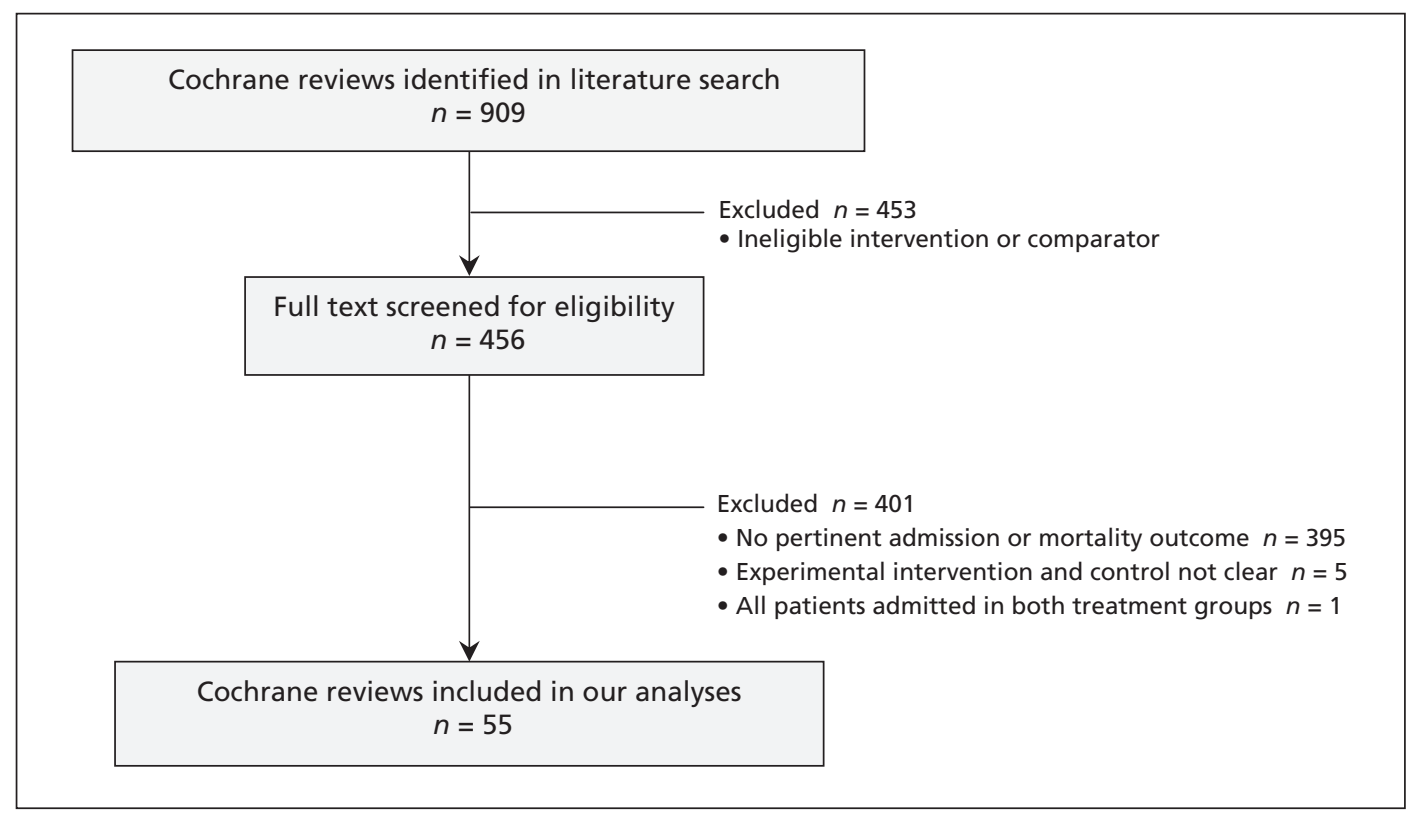

Figure 1: Selection of included reviews. 
with considerable between-comparison heterogeneity $\left(I^{2}=81 \%\right.$ [95\% CI 76\%-84\%], $\tau^{2}=$ 0.098 [95\% CI $0.074-0.125]$ ]). The average OR for death was 0.87 (95\% CI 0.82-0.93), with less heterogeneity $\left(I^{2}=42 \%\right.$ [95\% CI $18 \%-57 \%$ ], $\tau^{2}=0.014$ (95\% CI 0.004-0.025]).

\section{Admission versus mortality effects}

Concordant improvement of both outcomes was seen for 35 experimental treatments, and concordant harmful effects on both outcomes were seen for 9 experimental treatments. Concordant effects were more frequent than discordant effects $(44 \mathrm{v}$. 17 comparisons; binomial test $p<0.001$ ) (Table 2). Among the 17 comparisons with dis- cordant results, admission rates were decreased and mortality was increased in 9 comparisons; the opposite occurred in 8 comparisons.

Three comparisons had concordant effects that were significant for both outcomes. One comparison had significant effects for both outcomes that were discordant: thiazide with spironolactone increased the risk for readmission to hospital for respiratory deterioration in infants born preterm with established or developing chronic lung disease (OR 4.38, 95\% CI 1.2115.81), but decreased in-hospital mortality (OR $0.16,95 \%$ CI $0.03-0.81){ }^{37}$ There were 5 comparisons for which the $95 \%$ CIs of the effects on both outcomes did not overlap (Table 2).

Table 1 (part 1 of 3): Description of analyzed treatment comparisons

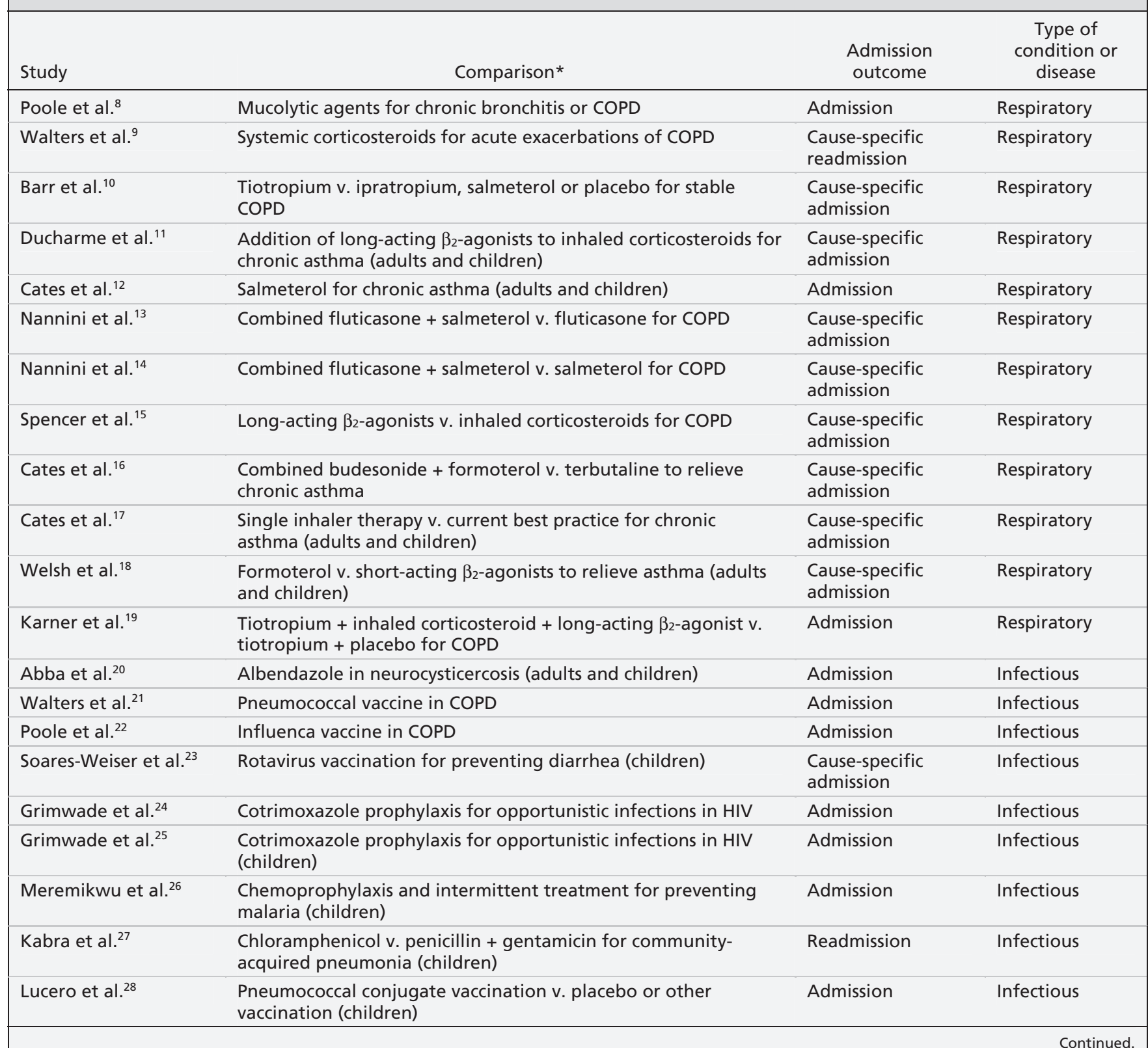


We found similar results in analyses using a fixed-effects model (data not shown) and when we limited our analysis to trials for which both outcomes were reported within the same trial (Table 2).

\section{Correlation of effect sizes}

We found no significant correlation between outcomes across the 61 comparisons (Figure 3, Table 3, Pearson $r=0.07, p=0.6$ ). Using admission effects from double-blinded trials only or from trials reporting on both outcomes showed similar results. In 2 subgroup analyses of 15 comparisons in the context of childbirth and pregnancy and 44 comparisons investigating allcause admission to hospital, we found a moder- ate correlation of borderline significance, which was not stable in our sensitivity analyses.

\section{Sensitivity and subgroup analyses}

None of the sensitivity and subgroup analyses showed significant correlations. However, some subgroups had very few comparisons, so inferences should be made cautiously (Table 3 ).

\section{Interpretation}

Our empirical evaluation suggests that admission and mortality outcomes in about one-third of cases yield different impressions about the merits of the experimental treatment.

Differences in mortality were typically small

Table 1 (part 2 of 3): Description of analyzed treatment comparisons

\begin{tabular}{|c|c|c|c|}
\hline Study & Comparison* & $\begin{array}{l}\text { Admission } \\
\text { outcome }\end{array}$ & $\begin{array}{l}\text { Type of } \\
\text { condition or } \\
\text { disease }\end{array}$ \\
\hline Thomas et al. ${ }^{29}$ & $\begin{array}{l}\text { Offer of influenza vaccine for health care workers who work } \\
\text { with older adults }\end{array}$ & Admission & Infectious \\
\hline Graves et al. ${ }^{30}$ & SPf66 vaccine for preventing malaria (children) & Admission & Infectious \\
\hline $\begin{array}{l}\text { Okebe et al. }{ }^{31} \\
\text { comparison A }\end{array}$ & $\begin{array}{l}\text { Iron supplements + antimalarial treatment in malaria-endemic } \\
\text { areas (children) }\end{array}$ & Admission & Infectious \\
\hline $\begin{array}{l}\text { Okebe et al. }{ }^{31} \\
\text { comparison C }\end{array}$ & Iron supplements for proven malaria (children) & Admission & Infectious \\
\hline $\begin{array}{l}\text { Okebe et al. }{ }^{31} \\
\text { comparison D }\end{array}$ & Iron supplements in malaria-endemic areas (children) & Admission & Infectious \\
\hline $\begin{array}{l}\text { Humphreys et al. }{ }^{33} \\
\text { comparison A }\end{array}$ & $\begin{array}{l}\text { Cotrimoxazole to prevent diarrhea in children with HIV or } \\
\text { exposure to maternal HIV }\end{array}$ & $\begin{array}{l}\text { Cause-specific } \\
\text { admission }\end{array}$ & Infectious \\
\hline $\begin{array}{l}\text { Humphreys et al. }{ }^{33} \\
\text { comparison B }\end{array}$ & Vitamin A to prevent diarrhea in children with HIV & $\begin{array}{l}\text { Cause-specific } \\
\text { admission }\end{array}$ & Infectious \\
\hline Phelps et al. ${ }^{34}$ & $\begin{array}{l}\text { D-Penicillamine to prevent retinopathy of prematurity in infants } \\
\text { born preterm }\end{array}$ & Readmission & Neonatal \\
\hline Halliday et al. ${ }^{35}$ & $\begin{array}{l}\text { Late postnatal corticosteroids for chronic lung disease in infants } \\
\text { born preterm }\end{array}$ & Readmission & Neonatal \\
\hline Halliday et al. ${ }^{36}$ & $\begin{array}{l}\text { Early postnatal corticosteroids to prevent chronic lung disease in } \\
\text { infants born preterm }\end{array}$ & Readmission & Neonatal \\
\hline Stewart et al. ${ }^{37}$ & $\begin{array}{l}\text { Thiazide with spironolactone in infants born preterm with (or } \\
\text { developing) chronic lung disease }\end{array}$ & $\begin{array}{l}\text { Cause-specific } \\
\text { readmission }\end{array}$ & Neonatal \\
\hline Cohen et al. ${ }^{41}$ & $\begin{array}{l}\text { Antibiotic prophylaxis for spontaneous bacterial peritonitis in } \\
\text { cirrhosis with ascites without gastrointestinal bleeding }\end{array}$ & Readmission & Infectious \\
\hline
\end{tabular}


and rarely reached nominal significance. Conversely, differences in admission rates tended to have a more dynamic range, with wider possible values and considerable heterogeneity across different comparisons and diseases, and some large effects might also be seen.

Although the point estimates were more likely to be concordant than not for both outcomes, the effect sizes showed almost no correlation between the 2 outcomes. In $27.9 \%$ of cases, the point estimates were discordant $(38.2 \%$ when only trials reporting both outcomes are included). Even when the statistical uncertainty was considered and the overlap of $95 \%$ CIs was analyzed, we found that effects on both outcomes significantly disagreed in about $10 \%$ of cases.

Our findings suggest that trial data on admission rates cannot be used to predict mortality, thus questioning the suitability of admission to hospital as a surrogate outcome for death. Moreover, this lack of good concordance in our analysis emphasizes that before mortality and admission rates are combined in composite outcomes, the assumption that the effects are concordant needs to be supported by sufficient evidence to have confidence in such an outcome. ${ }^{3,5}$

Situations may occur in which a positive correlation between admission rates and mortality

Table 1 (part 3 of 3): Description of analyzed treatment comparisons

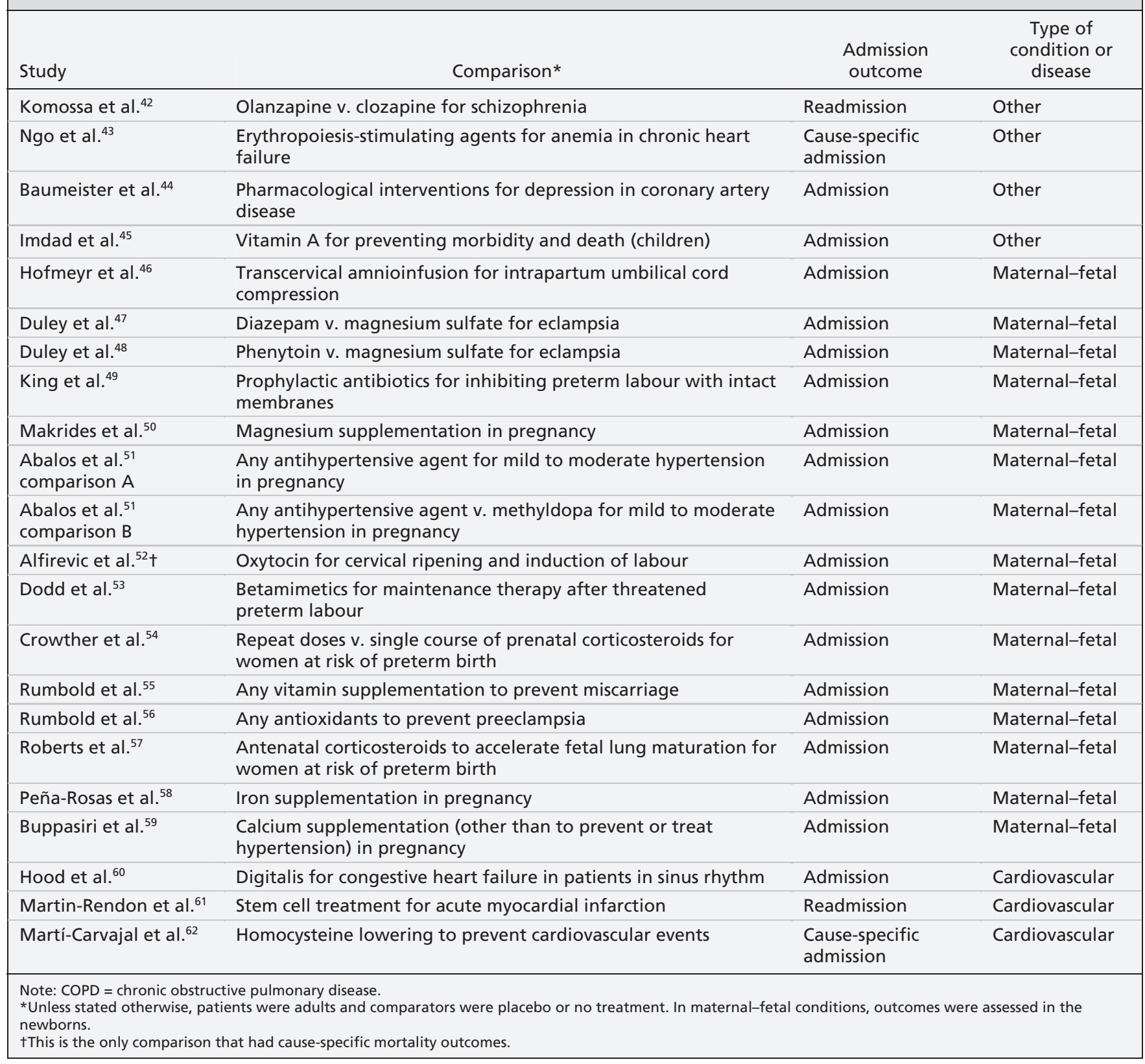


Study

Stewart et al. ${ }^{37}$

Abba et al. ${ }^{20}$

Okebe et al. ${ }^{31}$ comparison C

Duley et al. 48

Kabra et al. ${ }^{27}$

Humphreys et al. ${ }^{33}$ comparison A

Komossa et al. ${ }^{42}$

Dodd et al. ${ }^{53}$

Halliday et al. ${ }^{35}$

Crowther et al. ${ }^{54}$

Duley et al. ${ }^{47}$

Abalos et al. ${ }^{51}$ comparison A

Rumbold et al. ${ }^{56}$

Cates et al. ${ }^{12}$

Okebe et al. ${ }^{31}$ comparison B

Buppasiri et al. 59

Ducharme et al. ${ }^{11}$

Martí-Carvajal et al. ${ }^{62}$

Graves et al. ${ }^{30}$

Nannini et al. ${ }^{13}$

Lucero et al. ${ }^{28}$

Walters et al. ${ }^{21}$

Peña-Rosas et al. ${ }^{58}$

Spencer et al. ${ }^{15}$

Abalos et al. ${ }^{51}$ comparison B

Thomas et al. ${ }^{29}$

Nannini et al. ${ }^{14}$

Karner et al. ${ }^{19}$

Welsh et al. ${ }^{18}$

King et al. 49

Alfirevic et al. 52

Okebe et al. ${ }^{31}$ comparison D

Grimwade et al. 24

Rumbold et al. ${ }^{55}$

Walters et al. ${ }^{9}$

Halliday et al. ${ }^{36}$

Soares-Weiser et al.23

Makrides et al. ${ }^{50}$

Hofmeyr et al. 46

Cates et al. ${ }^{16}$

Cates et al. ${ }^{17}$

Poole et al. ${ }^{8}$

Grimwade et al. ${ }^{25}$

Barr et al. ${ }^{10}$

Imdad et al. ${ }^{45}$

Okebe et al. ${ }^{31}$ comparison A

Cohen et al. ${ }^{41}$

Roberts et al. ${ }^{57}$

Baumeister et al. ${ }^{44}$

Martin-Rendon et al. ${ }^{61}$

Ryan et al. ${ }^{38}$

Ngo et al. 43

Hood et al. ${ }^{60}$

Roderick et al. ${ }^{39}$

Baldwin et al. 40

Poole et al.22

Meremikwu et al. ${ }^{26}$

Humphreys et al. ${ }^{33}$ comparison B

Soares-Weiser et al. ${ }^{32}$ comparison $B$

Soares-Weiser et al. ${ }^{32}$ comparison A

Phelps et al. ${ }^{34}$

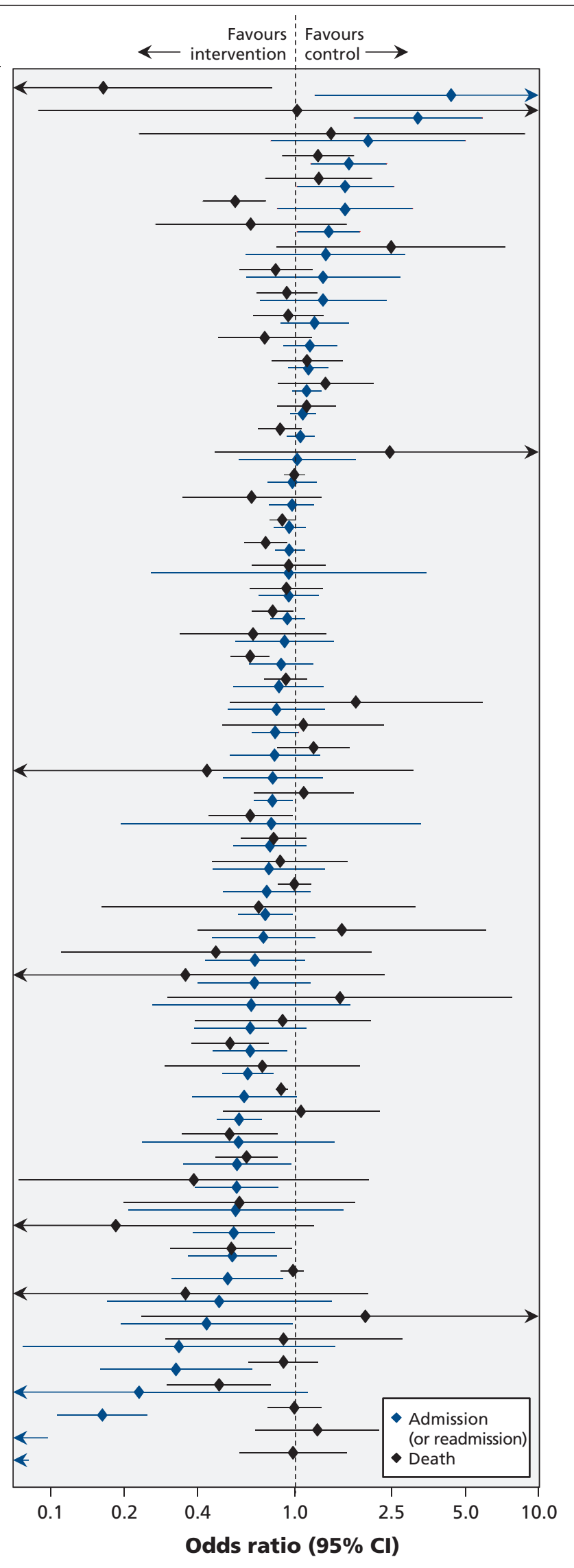

Figure 2: Concordance of treatment effects on admission to hospital and death. $\mathrm{Cl}=$ confidence interval. 
cannot reasonably be expected. Sometimes, patients admitted to hospital are not at risk of dying, requiring hospital care to avoid complications that are not life-threatening. Moreover, some interventions may show their true benefits not by lowering admission rates, but by increasing them - for example, an intervention that

Table 2: Concordance of effects of treatment on mortality and admission outcomes

\begin{tabular}{|c|c|c|}
\hline Direction of effect & $\begin{array}{l}\text { Analyses } \\
\text { including all } \\
\text { trials, no. (\%) } \\
\quad n=61\end{array}$ & $\begin{array}{c}\text { Analyses } \\
\text { including only } \\
\text { trials reporting } \\
\text { both outcomes } \\
\text { no. (\%) } \\
n=55^{*}\end{array}$ \\
\hline \multicolumn{3}{|l|}{ Concordant } \\
\hline Total no. of comparisons & $44(72.1)$ & $33(60.0)$ \\
\hline Benefit to both outcomes & $35(57.4) \dagger$ & 25 (45.4)‡ \\
\hline Harm to both outcomes & $9(14.8)$ & $8(14.5)$ \\
\hline \multicolumn{3}{|l|}{ Discordant } \\
\hline Total no. of comparisons & 17 (27.9) & $21(38.2)$ \\
\hline $\begin{array}{l}\text { Benefit to mortality, harm to } \\
\text { admission }\end{array}$ & $8(13.1) \dagger$ & $7(12.7)$ \\
\hline $\begin{array}{l}\text { Benefit admission, harm to } \\
\text { mortality }\end{array}$ & $9(14.8)$ & $14(25.4)$ \\
\hline $\begin{array}{l}\text { Comparisons with non-overlapping } \\
\text { Cls of treatment effects }\end{array}$ & $5 \quad(8.2) \dagger$ & $5 \quad(9.1)$ \\
\hline \multicolumn{3}{|c|}{$\begin{array}{l}\text { Note: } \mathrm{Cl}=95 \% \text { confidence interval. } \\
\text { *In } 1 \text { comparison, the odds ratio was exactly } 1 \text {; thus, concordance or discordance could not } \\
\text { be stated. } \\
\text { three comparisons with statistically significant treatment effects for both outcomes. } \\
\text { fOne comparison with statistically significant treatment effects for both outcomes. }\end{array}$} \\
\hline
\end{tabular}

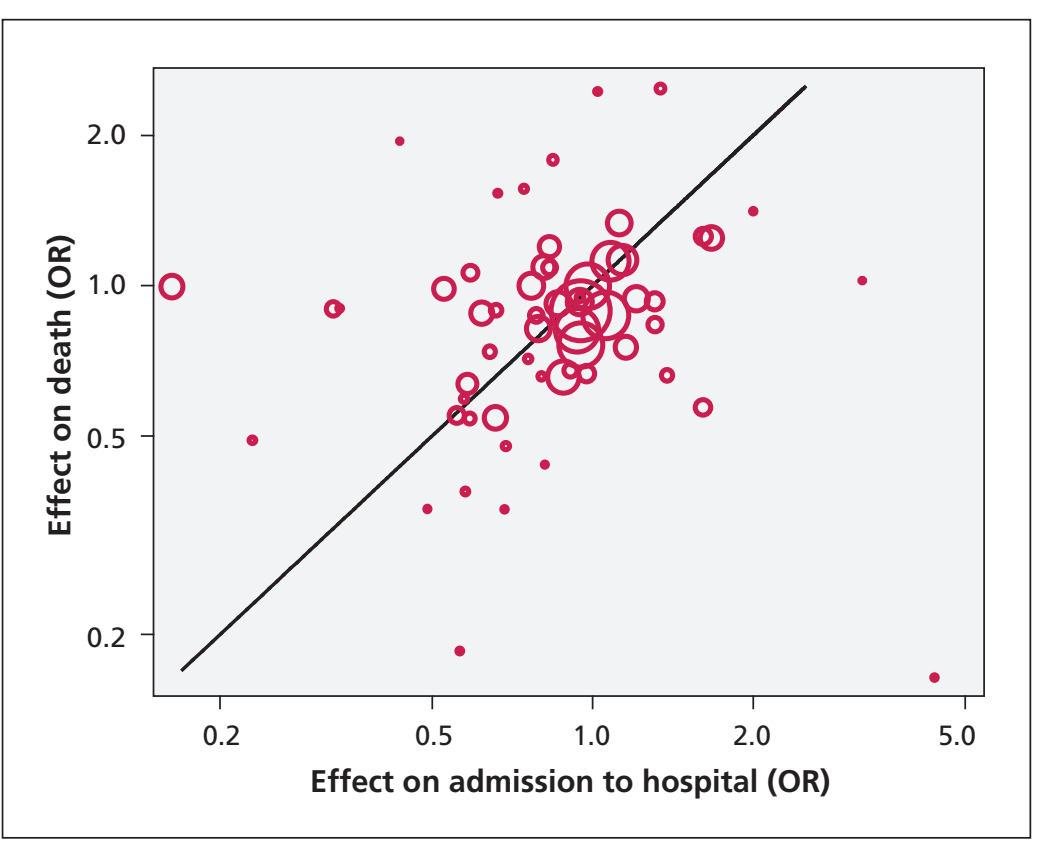

Figure 3: Correlation of treatment effects on admission to hospital versus death. $\mathrm{OR}=$ odds ratio. Note: Two components with admission effects outside of the range $(O R<0.05)$ are not shown. ${ }^{32,34}$ allows the diagnosis of early symptoms or stabilizes a patient's condition so that he or she may reach a hospital alive. In these cases, admissions would be less an indicator (or proxy) of lifethreatening health problems than an indicator of good medical care. Thus, in such an example, decreasing admission rates could not be used as a measure of increasing quality of care.

In some diseases, death may be an uncommon event, so other outcomes (including admission to hospital) may attract primary attention. However, no matter how uncommon, deaths cannot be discarded. Owing to the wide perspective of our approach, we considered comparisons that may not be intuitively associated with clear-cut clinical effects on mortality; for example, vitamin supplementation for preventing miscarriage, ${ }^{55}$ mucolytics for chronic obstructive pulmonary disorder ${ }^{8}$ or treatments for schizophrenia. ${ }^{42}$ Even in such cases, death was not uncommon, with corresponding event rates in the control groups of included trials of $8.9 \%,{ }^{55} 3.4 \%$ and $2.4 \% .^{42}$ Comparisons with very low event rates (fewer than 5 events in an entire meta-analysis) were excluded, because treatment effect estimates from such analyses would be quite unstable and imprecise.

Admission rates can be useful in assessing medical interventions. In some cases, admissions may be a major aspect of the cost of managing a disease and may even be the most patientrelevant outcome. However, it is also probable that decisions to admit patients are subjective, ${ }^{63-67}$ and the threshold to admit may vary across populations, clinical centres, settings and health care systems. ${ }^{68-70}$ Conversely, mortality is unlikely to be equally affected by these factors. This is in line with the dynamic range of admission effect estimates we saw and their accompanying heterogeneity. The between-comparison variance for effects on admission was higher than that for effects on death, and much of the observed heterogeneity could be due to true differences in the underlying interventions, reflecting the clinical diversity of the included comparisons. Conversely, mortality effects were clustered more closely together and showed only moderate heterogeneity, even across diverse comparisons.

\section{Comparison with other studies}

An analysis of parallel group RCTs that had a composite primary outcome found that, in half of the trials, death was combined with hospital admission (or admission-requiring procedures), and data on the individual components of the composite outcome were often missing. ${ }^{3}$ Few of the authors of the included trials provided a clear rationale supporting the use of the composite outcome (3\% of trials). The results of our analysis 
clearly emphasize the necessity of providing such rationale before combining these outcomes. Our results agree with those of a systematic review of 167 trials that had composite primary outcomes with mortality components. ${ }^{4}$ In $36 \%$ of those trials, results were significant for the composite outcome, but not for the mortality component (the opposite occurred in $4 \%$ of the trials). Moreover, in $13 \%$ of the trials, reporting for individual components of the composite outcome was inadequate.

\section{Limitations}

Even though we screened the entire Cochrane database, the accumulated data are still limited; the estimates of the effect sizes are uncertain for many meta-analyses. In addition, our analysis does not directly address the question of surrogacy - that is, whether admission to hospital can be a surrogate outcome for death. Such an analysis would require individual-level data and, ideally, could be done in trials that have already shown large effect sizes for the main outcome of interest (death). ${ }^{71,72}$ However, because admission to hospital is more common than death for most of the diseases studied in the trials we included in our analysis, admission to hospital would probably mislabel many patients' illnesses as terminal if it were used as a strict surrogate of death.

Table 3: Correlation of treatment effects on mortality and admission outcomes

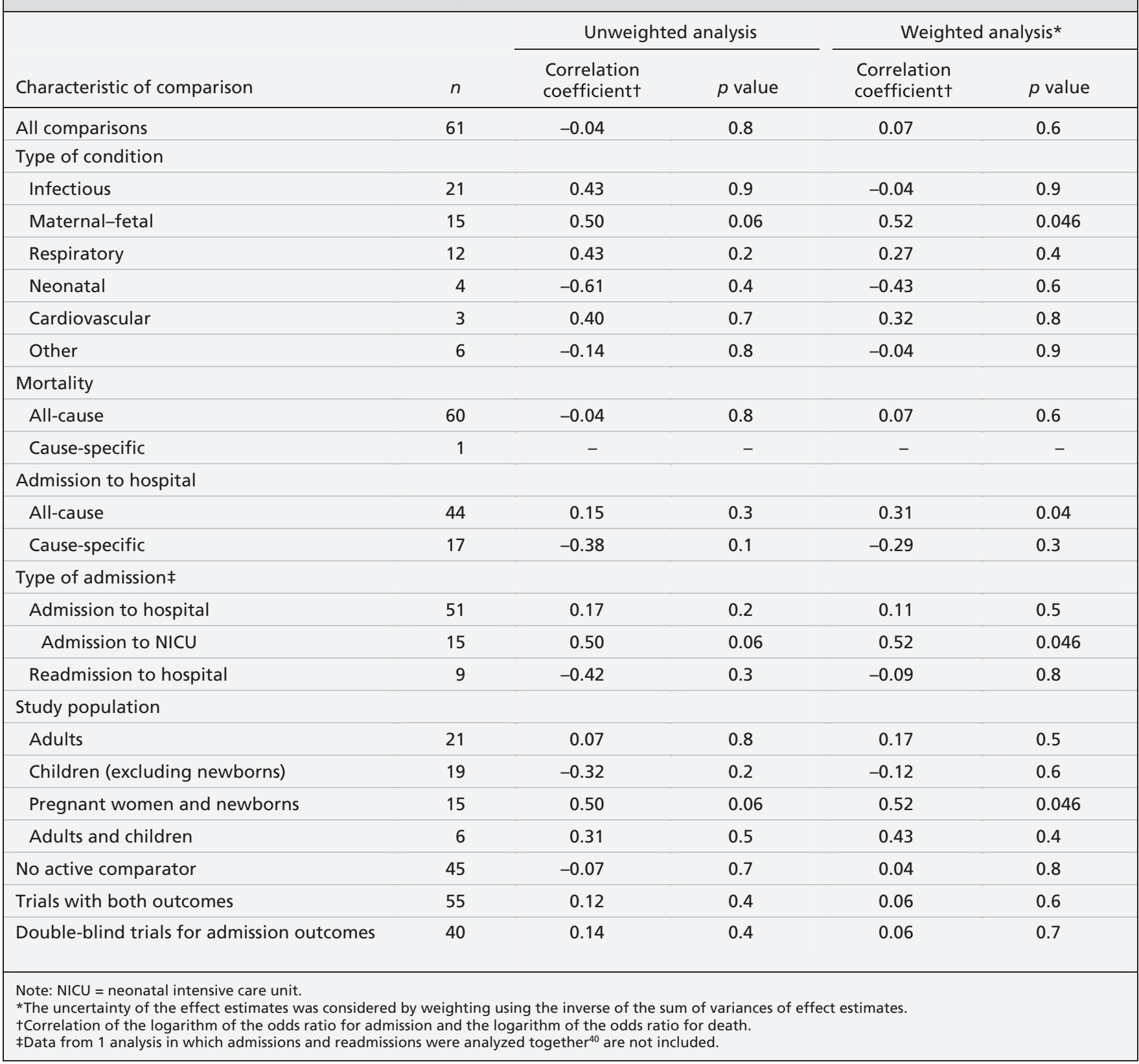


We accepted that data from some primary studies were included in meta-analyses on different topics. In addition, of the 182 trials with admissions data, only 115 were double-blind, and the double-blinding may not have been totally successful in masking allocation. However, there was no strong evidence to suggest that concordance was better in these trials for admission outcomes than for mortality outcomes.

\section{Conclusion}

Effect sizes for admission rates and mortality do not appear to be correlated. Both outcomes may convey useful information, which should be reported separately. A clear rationale should be provided when these outcomes are combined as a composite outcome in clinical trials. When death is clearly the outcome of interest, randomized evidence should be properly powered to address differences in mortality rather than differences in admission rates alone. Extrapolating the benefits of admission to hospital to a reduced risk of death would be unreliable and should be avoided.

\section{References}

1. Jencks SF, Williams MV, Coleman EA. Rehospitalizations among patients in the Medicare fee-for-service program. $N$ Engl J Med 2009;360:1418-28.

2. Joynt KE, Jha AK. Thirty-day readmissions - truth and consequences. N Engl J Med 2012;366:1366-9.

3. Cordoba G, Schwartz L, Woloshin S, et al. Definition, reporting, and interpretation of composite outcomes in clinical trials: systematic review. BMJ 2010;341:c3920.

4. Freemantle N, Calvert M, Wood J, et al. Composite outcomes in randomized trials: Greater precision but with greater uncertainty? JAMA 2003;289:2554-9.

5. Montori VM, Permanyer-Miralda G, Ferreira-Gonzalez I, et al. Validity of composite end points in clinical trials. BMJ 2005; 330:594-6.

6. Wyse DG, Slee A, Epstein AE, et al. Alternative endpoints for mortality in studies of patients with atrial fibrillation: the AFFIRM study experience. Heart Rhythm 2004;1:531-7.

7. Lau J, Ioannidis JP, Schmid CH. Quantitative synthesis in systematic reviews. Ann Intern Med 1997;127:820-6.

8. Poole P, Black PN. Mucolytic agents for chronic bronchitis or chronic obstructive pulmonary disease. Cochrane Database Syst Rev 2010;(2):CD001287.

9. Walters JA, Gibson PG, Wood-Baker R, et al. Systemic corticosteroids for acute exacerbations of chronic obstructive pulmonary disease. Cochrane Database Syst Rev 2009;(1):CD001288.

10. Barr RG, Bourbeau J, Camargo CA. Tiotropium for stable chronic obstructive pulmonary disease. Cochrane Database Syst Rev 2005;(2):CD002876.

11. Ducharme FM, Ni Chroinin M, Greenstone I, et al. Addition of long-acting $\beta 2$-agonists to inhaled corticosteroids versus same dose inhaled corticosteroids for chronic asthma in adults and children. Cochrane Database Syst Rev 2010;(5):CD005535.

12. Cates CJ, Cates MJ. Regular treatment with salmeterol for chronic asthma: serious adverse events. Cochrane Database Syst Rev 2008; (3):CD006363.

13. Nannini LJ, Cates CJ, Lasserson TJ, et al. Combined corticosteroid and long-acting $\beta$-agonist in one inhaler versus inhaled steroids for chronic obstructive pulmonary disease. Cochrane Database Syst Rev 2007;(4):CD006826.

14. Nannini LJ, Cates CJ, Lasserson TJ, et al. Combined corticosteroid and long-acting beta-agonist in one inhaler versus longacting beta-agonists for chronic obstructive pulmonary disease. Cochrane Database Syst Rev 2007;(4):CD006829.

15. Spencer S, Karner C, Cates CJ, et al. Inhaled corticosteroids versus long-acting beta2-agonists for chronic obstructive pulmonary disease. Cochrane Database Syst Rev 2011;(12):CD007033.

16. Cates CJ, Lasserson TJ. Combination formoterol and inhaled steroid versus beta2-agonist as relief medication for chronic asthma in adults and children. Cochrane Database Syst Rev 2009; (1):CD007085.

17. Cates CJ, Lasserson TJ. Combination formoterol and budesonide as maintenance and reliever therapy versus inhaled steroid maintenance for chronic asthma in adults and children. Cochrane Database Syst Rev 2009;(2):CD007313.

18. Welsh EJ. Cates CJ. Formoterol versus short-acting beta-agonists as relief medication for adults and children with asthma. Cochrane Database Syst Rev 2010;(9):CD008418.

19. Karner C, Cates CJ. Combination inhaled steroid and long-acting beta2-agonist in addition to tiotropium versus tiotropium or combination alone for chronic obstructive pulmonary disease. Cochrane Database Syst Rev 2011;(3):CD008532.

20. Abba K, Ramaratnam S, Ranganathan LN. Anthelmintics for people with neurocysticercosis. Cochrane Database Syst Rev 2010; (3):CD000215.

21. Walters JA, Smith S, Poole P, et al. Injectable vaccines for preventing pneumococcal infection in patients with chronic obstructive pulmonary disease. Cochrane Database Syst Rev 2010; (11):CD001390.

22. Poole PJ, Chacko Emme E, Wood-Baker R, et al. Influenza vaccine for patients with chronic obstructive pulmonary disease. Cochrane Database Syst Rev 2006; (1):CD002733.

23. Soares-Weiser K, Goldberg E, Tamimi G, et al. Rotavirus vaccine for preventing diarrhoea. Cochrane Database Syst Rev 2004; (1):CD002848.

24. Grimwade K, Swingler GH. Cotrimoxazole prophylaxis for opportunistic infections in adults with HIV. Cochrane Database Syst Rev 2003;(3):CD003108

25. Grimwade K, Swingler GH. Cotrimoxazole prophylaxis for opportunistic infections in children with HIV infection. Cochrane Database Syst Rev 2006;(1):CD003508.

26. Meremikwu MM, Donegan S, Esu E. Chemoprophylaxis and intermittent treatment for preventing malaria in children. Cochrane Database Syst Rev 2008;(2):CD003756.

27. Kabra SK, Lodha R, Pandey RM. Antibiotics for communityacquired pneumonia in children. Cochrane Database Syst Rev 2010;(3):CD004874.

28. Lucero MG, Dulalia VE, Nillos LT, et al. Pneumococcal conjugate vaccines for preventing vaccine-type invasive pneumococcal disease and X-ray defined pneumonia in children less than two years of age. Cochrane Database Syst Rev 2009;(4):CD004977.

29. Thomas RE, Jefferson T, Lasserson TJ. Influenza vaccination for healthcare workers who work with the elderly. Cochrane Database Syst Rev 2010;(2):CD005187.

30. Graves PM, Gelband H. Vaccines for preventing malaria (SPf66). Cochrane Database Syst Rev 2006;(2):CD005966.

31. Okebe JU, Yahav D, Shbita R, et al. Oral iron supplements for children in malaria-endemic areas. Cochrane Database Syst Rev 2011;(10):CD006589.

32. Soares-Weiser K, MacLehose H, Ben-Aharon I, et al. Vaccines for preventing rotavirus diarrhoea: vaccines in use. Cochrane Database Syst Rev 2010;(5):CD008521.

33. Humphreys EH, Smith NM, Azman H, et al. Prevention of diarrhoea in children with HIV infection or exposure to maternal HIV infection. Cochrane Database Syst Rev 2010;(6):CD008563.

34. Phelps DL, Lakatos L, Watts J. D-Penicillamine for preventing retinopathy of prematurity in preterm infants. Cochrane Database Syst Rev 2001;(1):CD001073.

35. Halliday HL, Ehrenkranz RA, Doyle LW. Late ( $>7$ days) postnatal corticosteroids for chronic lung disease in preterm infants. Cochrane Database Syst Rev 2009;(1):CD001145.

36. Halliday HL, Ehrenkranz RA, Doyle LW. Early ( $<8$ days) postnatal corticosteroids for preventing chronic lung disease in preterm infants. Cochrane Database Syst Rev 2010;(1):CD001146.

37. Stewart A, Brion LP, Ambrosio-Perez I. Diuretics acting on the distal renal tubule for preterm infants with (or developing) chronic lung disease. Cochrane Database Syst Rev 2011;(9):CD001817.

38. Ryan G, Singh M, Dwan K. Inhaled antibiotics for long-term therapy in cystic fibrosis. Cochrane Database Syst Rev 2011;(3): CD001021.

39. Roderick PJ, Willis NS, Blakeley S, et al. Correction of chronic metabolic acidosis for chronic kidney disease patients. Cochrane Database Syst Rev 2007;(1):CD001890.

40. Baldwin C, Weekes CE. Dietary advice with or without oral nutritional supplements for disease-related malnutrition in adults. Cochrane Database Syst Rev 2011;(9):CD002008.

41. Cohen MJ, Sahar T, Benenson S, et al. Antibiotic prophylaxis for spontaneous bacterial peritonitis in cirrhotic patients with ascites, without gastrointestinal bleeding. Cochrane Database Syst Rev 2009; (2):CD004791.

42. Komossa K, Rummel-Kluge $\mathrm{C}$, Hunger $\mathrm{H}$, et al. Olanzapine versus other atypical antipsychotics for schizophrenia. Cochrane Database Syst Rev 2010;(3):CD006654. 
43. Ngo K, Kotecha D, Walters JA, et al. Erythropoiesis-stimulating agents for anaemia in chronic heart failure patients. Cochrane Database Syst Rev 2010;(1):CD007613.

44. Baumeister H, Hutter N, Bengel J. Psychological and pharmacological interventions for depression in patients with coronary artery disease. Cochrane Database Syst Rev 2011;(9):CD008012.

45. Imdad A, Herzer K, Mayo-Wilson E, et al. Vitamin A supplementation for preventing morbidity and mortality in children from 6 months to 5 years of age. Cochrane Database Syst Rev 2010; (12):CD008524

46. Hofmeyr GJ, Lawrie TA. Amnioinfusion for potential or suspected umbilical cord compression in labour. Cochrane Database Syst Rev 2012;(1):CD000013.

47. Duley L, Henderson-Smart DJ, Walker GJA, et al. Magnesium sulphate versus diazepam for eclampsia. Cochrane Database Syst Rev 2010;(12):CD000127.

48. Duley L, Henderson-Smart DJ, Chou D. Magnesium sulphate versus phenytoin for eclampsia. Cochrane Database Syst Rev 2010;(10):CD000128.

49. King JF, Flenady V, Murray L. Prophylactic antibiotics for inhibiting preterm labour with intact membranes. Cochrane Database Syst Rev 2002;(4):CD000246.

50. Makrides M, Crowther CA. Magnesium supplementation in pregnancy. Cochrane Database Syst Rev 2001;(4):CD000937.

51. Abalos E, Duley L, Steyn DW, et al. Antihypertensive drug therapy for mild to moderate hypertension during pregnancy. Cochrane Database Syst Rev 2007;(1):CD002252.

52. Alfirevic Z, Kelly AJ, Dowswell T. Intravenous oxytocin alone for cervical ripening and induction of labour. Cochrane Database Syst Rev 2009;(4):CD003246.

53. Dodd JM, Crowther CA, Dare MR, et al. Oral betamimetics for maintenance therapy after threatened preterm labour. Cochrane Database Syst Rev 2006;(1):CD003927.

54. Crowther CA, McKinlay CJD, Middleton P, et al. Repeat doses of prenatal corticosteroids for women at risk of preterm birth for improving neonatal health outcomes. Cochrane Database Syst Rev 2011;(6):CD003935.

55. Rumbold A, Middleton P, Pan N, et al. Vitamin supplementation for preventing miscarriage. Cochrane Database Syst Rev 2011;(1): CD004073.

56. Rumbold A, Duley L, Crowther CA, et al. Antioxidants for preventing pre-eclampsia. Cochrane Database Syst Rev 2008;(1): CD004227.

57. Roberts D, Dalziel SR. Antenatal corticosteroids for accelerating fetal lung maturation for women at risk of preterm birth. Cochrane Database Syst Rev 2006;(3):CD004454.

58. Peña-Rosas JP, Viteri FE. Effects and safety of preventive ora iron or iron+folic acid supplementation for women during pregnancy. Cochrane Database Syst Rev 2009;(4):CD004736.

59. Buppasiri P, Lumbiganon P, Thinkhamrop J, et al. Calcium supplementation (other than for preventing or treating hypertension) for improving pregnancy and infant outcomes. Cochrane Database Syst Rev 2011;(10):CD007079.

60. Hood WB, Dans AL, Guyatt GH, et al. Digitalis for treatment of heart failure in patients in sinus rhythm. Cochrane Database Syst Rev 2004;(2):CD002901.

61. Martin-Rendon E, Brunskill S, Doree C, et al. Stem cell treatment for acute myocardial infarction. Cochrane Database Syst Rev 2008;(4):CD006536

62. Martí-Carvajal AJ, Solà I, Lathyris D, et al. Homocysteine lowering interventions for preventing cardiovascular events. Cochrane Database Syst Rev 2009;(4):CD006612.
63. Dean NC, Jones JP, Aronsky D, et al. Hospital admission decision for patients with community-acquired pneumonia: variability among physicians in an emergency department. Ann Emerg Med 2012;59:35-41.

64. Vance CW, Lee MO, Holmes JF, et al. Variation in specialists' reported hospitalization practices of children sustaining blunt head trauma. West J Emerg Med 2013;14:29-36.

65. Sokolove PE, Kuppermann N, Vance CW, et al. Variation in specialists' reported hospitalization practices of children sustaining blunt abdominal trauma. West J Emerg Med 2013;14: $37-46$.

66. Gaucher N, Bailey B, Gravel J. Impact of physicians' characteristics on the admission risk among children visiting a pediatric emergency department. Pediatr Emerg Care 2012;28:120-4.

67. McDermott C, Coppin R, Little P, et al. Hospital admissions from nursing homes: a qualitative study of GP decision making. Br J Gen Pract 2012;62:e538-45.

68. Coon JT, Martin A, Abdul-Rahman AK, et al. Interventions to reduce acute paediatric hospital admissions: a systematic review. Arch Dis Child 2012;97:304-11.

69. Benbassat J, Taragin M. Hospital readmissions as a measure of quality of health care: advantages and limitations. Arch Intern Med 2000;160:1074-81.

70. Kociol RD, Lopes RD, Clare R, et al. International variation in and factors associated with hospital readmission after myocardial infarction. JAMA 2012;307:66-74.

71. Molenberghs G, Burzykowski T, Alonso A, et al. A perspective on surrogate endpoints in controlled clinical trials. Stat Methods Med Res 2004;13:177-206.

72. Buyse M, Sargent DJ, Grothey A, et al. Biomarkers and surrogate end points - the challenge of statistical validation. Nat Rev Clin Oncol 2010;7:309-17.

Affiliations: Stanford Prevention Research Center (Hemkens, Ioannidis), Department of Medicine, Stanford University School of Medicine, Stanford, Calif.; Basel Institute for Clinical Epidemiology and Biostatistics (Hemkens), University Hospital Basel, Basel, Switzerland; Department of Pediatrics (Contopoulos-Ioannidis), Division of Infectious Diseases, Stanford University School of Medicine, Stanford, Calif.; Health Policy Research (Contopoulos-Ioannidis), Palo Alto Medical Foundation Research Institute, Palo Alto, Calif.; Department of Health Research and Policy (Ioannidis), Stanford University School of Medicine; Department of Statistics (Ioannidis), Stanford University School of Humanities and Sciences, Stanford, Calif.

Contributors: All of the authors conceived the study, analyzed the data, interpreted the results, drafted the manuscript and approved the final version submitted for publication.

Funding: Supported by The Commonwealth Fund, a private independent foundation based in New York, New York. The views presented here are those of the authors and not necessarily those of The Commonwealth Fund, its directors, officers or staff. The funders had no role in the design or conduct of the study; the collection, management, analysis or interpretation of the data; or the preparation, review or approval of the manuscript. 